\title{
A coesão referencial em textos traduzidos do inglês para o português: a questão dos sujeitos nulos ${ }^{1}$
}

\author{
Anabela Gonçalves \& Madalena Colaço
}

Universidade de Lisboa, Faculdade de Letras, Centro de Linguística

\begin{abstract}
:
Understanding and writing a text arise from several factors. Among them, coreference relations, which allow for the identification of the referents of linguistic expressions, are of particular importance, since they ensure referential cohesion and, thus, contribute to text cohesion. One context in which recognizing referential relations is crucial involves reference chains with anaphoric pronouns. Although all languages exhibit coreference relations, the linguistic means to establish them may vary. Thus, in the context of translation, maintaining reference chains often implies the use of adaptation strategies: when working with non-null subject source languages, such as English, and null subject target languages, such as Portuguese, translators should recognize the contexts in which, in the latter, they may or must omit the subject, without affecting interpretation nor creating vagueness, conflict of interpretations or referential ambiguity. In this work, some data about reference chains in the context of English to Portuguese translation is discussed. We identify the main mismatches in translations done by university students and present clues to help train students in translation, promoting their mastering of the grammatical and textual conditions that determine the omission vs. the realization of the subject. The results show that the main problems result either from calque of the source language properties or from the overgeneralization of null subject contexts in the target language.
\end{abstract}

Keywords: reference chains, referential cohesion, null subject, translation

Palavras-chave: cadeias de referência, coesão referencial, sujeito nulo, tradução

\section{Introdução}

Compreender e escrever um texto, no âmbito da tradução ou não, resulta da combinação de vários fatores. Entre eles, são de particular importância as relações de correferência entre constituintes, que permitem a identificação dos referentes das expressões linguísticas, assegurando a coesão referencial e, assim, contribuindo para a coesão textual, um dos parâmetros da textualidade referidos por Beaugrande \& Dressler (1981) como essenciais para que um texto seja entendido enquanto tal e não como uma mera sequência de frases que se organizam linearmente (ver também Duarte, 2003; Mendes, 2013). Um dos contextos em que o reconhecimento das relações referenciais é crucial envolve cadeias de referência contendo formas pronominais anafóricas, nulas ou com realização lexical, que dependem de uma expressão referencial para estabelecer o seu próprio referente.

Embora as relações de correferência estejam presentes nas várias línguas, os meios linguísticos para as estabelecer podem variar. Assim, no contexto da tradução, a manutenção das cadeias de referência que ocorrem no texto de partida implica frequentemente a utilização de estratégias de adaptação devido a diferenças

\footnotetext{
${ }^{1}$ Este trabalho foi desenvolvido no Centro de Linguística da Universidade de Lisboa (CLUL), unidade de I\&D financiada pela Fundação para a Ciência e a Tecnologia ( UID/LIN/00214/2019).

Agradecemos os comentários que nos foram feitos durante o XXXIV Encontro Nacional da Associação Portuguesa de Linguística, bem como os comentários e as sugestões dos revisores da primeira versão deste texto.
} 
relativamente à forma como na língua de chegada se pode construir essas cadeias e à interpretação que se obtém através das mesmas.

Neste trabalho, serão objeto de descrição e análise produções escritas resultantes de traduções de inglês para português realizadas em contexto académico. ${ }^{2}$ Tratando-se de línguas que se distinguem quanto à possibilidade de ocorrência de sujeitos nulos em frases finitas, centrar-nos-emos em particular em cadeias de referência que envolvam expressões pronominais nulas e com realização lexical em posição de sujeito. ${ }^{3}$ Partindo de um estudo anterior (Gonçalves \& Colaço, 2018), são nossos objetivos: (i) distinguir os contextos em que, em português, o tradutor pode omitir ou realizar o sujeito daqueles em que tem de o omitir ou de o realizar; (ii) identificar, em traduções realizadas por estudantes universitários, os principais problemas na construção de cadeias de referência que possam ou tenham de integrar sujeitos nulos ou sujeitos realizados em português; (iii) contribuir para a formulação de generalizações sobre a formação das referidas cadeias de referência que possam constituir pistas linguísticas para o tradutor no momento em que tem de decidir entre omitir ou realizar o sujeito na língua de chegada.

O trabalho organiza-se da seguinte forma: na Secção 2, apresentaremos os aspetos essenciais da coesão referencial, incluindo uma descrição dos contextos do português que permitem ou impedem a ocorrência de sujeitos nulos; na Secção 3, procede-se à descrição de dados recolhidos de traduções realizadas em contexto académico que apresentam problemas, em particular no que diz respeito à construção de cadeias de referência que envolvam formas pronominais, nulas ou realizadas, na posição de sujeito de frases finitas; por último, na Secção 4, enunciam-se as conclusões gerais do trabalho.

\section{Coesão referencial}

A coesão textual é referida por diversos autores (cf. Beaugrande \& Dressler, 1981, entre outros) como uma propriedade de textualidade, no sentido em que é um dos fatores que tornam um texto reconhecível como tal. ${ }^{4}$ Assegurada através da confluência de uma variedade de elementos que ligam as unidades que, em diferentes planos, ocorrem na superfície textual - desde as palavras que ocorrem numa frase, até aos diferentes períodos e parágrafos de texto, ou mesmo sequências textuais constituídas por conjuntos de parágrafos -, a coesão textual é, assim, vista como uma condição para a consideração do texto como um objeto uno.

Entre os fatores que asseguram a coesão textual, são de particular importância as relações de correferência que se estabelecem entre as expressões nominais usadas para referir entidades, que resultam na conectividade de duas ou mais expressões, muitas vezes com diferentes realizações linguísticas, que são interpretadas como referindo a mesma entidade num determinado mundo, ao longo de um texto. Ligadas por correferência, essas várias expressões constituem uma cadeia referencial. A identificação das cadeias referenciais, que assenta na identificação dos referentes das expressões nominais e das relações referenciais que se estabelecem entre elas, é, então, uma condição para a compreensão do texto.

\footnotetext{
${ }^{2}$ No presente trabalho, sempre que usarmos o termo português estamos a referir-nos à variedade europeia. Nos casos em que nos referimos à variedade brasileira, usaremos explicitamente português brasileiro $(P B)$.

${ }^{3}$ Veja-se Costa, Matos \& Luegi (2010), um estudo sobre o processamento anafórico das várias categorias vazias nominais que ocorrem na posição de sujeito de frases finitas em português europeu, nomeadamente: pro, variável-wh e cópia de movimento de NP. Neste trabalho, as autoras mostram que existem diferenças no que diz respeito aos custos de processamento das relações anafóricas que envolvem os vários tipos de sujeitos omitidos.

${ }^{4}$ Beaugrande \& Dressler (1981) consideram a existência de sete propriedades de textualidade: a coesão, a coerência, a informatividade, a aceitabilidade, a intencionalidade, a situacionalidade e a intertextualidade.
} 


\subsection{Expressões referenciais e (in)dependência referencial}

As expressões linguísticas associadas à propriedade da referência, ou seja, que são usadas para referir entidades, são de diferentes tipos: desde as expressões nominais centradas num nome próprio, até descrições definidas ou expressões pronominais (cf. (1)-(3), respetivamente). A referência pode, inclusivamente, estar associada a expressões sem realização lexical, como é o caso do sujeito nulo nas línguas que o admitem (cf. (4)): apesar de o sujeito poder, nestas línguas, não ser realizado, a sua interpretação, ou seja, o reconhecimento da entidade que ele refere, é fundamental para a compreensão da frase e, consequentemente, do texto.

(1) O Pedro viajou sozinho.

(2) O Pedro viajou para as ilhas gregas.

(3) Ele viajou sozinho.

(4) O Pedro tem dois irmãos, mas [-] viaja sozinho frequentemente.

De acordo com Mendes (2013), as relações que se estabelecem entre as expressões referenciais que ocorrem num texto podem ser avaliadas de acordo com dois parâmetros: (i) a existência ou não de correferência entre elas; (ii) a sua independência ou dependência em termos referenciais. Com efeito, existem expressões referenciais que são autónomas do ponto de vista referencial, no sentido em que não dependem de outras expressões no texto para estabelecerem a sua referência: é o caso de expressões como o Pedro ou as ilhas gregas, nos exemplos (1) e (2). É também o caso de expressões cujo referente está presente no contexto da enunciação e que, por isso, correspondem a elementos dêiticos, como as que ocorrem em (5) e (6), ou como o pronome que ocorre em (3), se a frase for, por exemplo, produzida oralmente, numa situação de comunicação presencial, em que o falante que a enuncia aponta para a entidade que pretende referir.

(5) O Pedro pediu à Ana para ela lhe emprestar isto / este livro.

(6) [-] Emprestei o livro à Ana.

No entanto, paralelamente a estas, existem expressões que dependem referencialmente de outras que ocorrem no mesmo texto - que funcionam, por isso, como o seu antecedente - e que apenas na sua relação com elas - uma relação anafórica ${ }^{5}$ - veem estabelecido o seu referente. Estão nesta situação os pronomes e os sujeitos nulos que ocorrem em (4), (5) e (7), tal como o pronome que ocorre em (3), se a frase estiver inserida num texto escrito em que a interpretação desse pronome seja anafórica. Assim, os sujeitos nulos e os pronomes correspondem, neste sentido, a expressões anafóricas.

(7) O Pedro telefonou aos amigos e [-] pediu-lhes que $o$ fossem buscar.

Como é referido em Mendes (2013), a construção de cadeias referenciais num texto obedece a alguns princípios gerais de organização. Assim, por exemplo, normalmente, as cadeias referenciais são encabeçadas por expressões referencialmente autónomas ou mais específicas, sendo seguidas de expressões dependentes com as quais se estabelecem relações anafóricas. Por outro lado, depois de apresentada a entidade no texto, as estratégias usadas para a retoma da referência variam em função da unidade textual em que ocorrem. Assim, "no interior do mesmo parágrafo, o referente é geralmente retomado através de expressões pronominais ou de expressões foneticamente não realizadas (como, por exemplo, os pronomes nulos), enquanto no início de um novo parágrafo se recorre tipicamente a expressões nominais que constituem quer reiterações (totais ou parciais) quer paráfrases (como a anáfora lexical)" (Mendes, 2013: 1709). No entanto, como veremos na secção 2.3, a questão da distribuição das expressões anafóricas não é simples e tem sido alvo de diferentes propostas.

${ }^{5}$ No âmbito deste trabalho, consideraremos o termo "anáfora" enquanto sinónimo de anáfora discursiva (cf., por exemplo, Clark \& Parikh, 2007; Huang, 2000) e não como anáfora sintática (cf., entre outros, Reinhart, 1983; Safir, 2004). A ocorrência destes dois tipos de anáforas é influenciada por diferentes fatores e regulada por mecanismos distintos, que não discutiremos no presente trabalho. 


\subsection{Os processos de retoma do referente}

Após a introdução de um referente no discurso/texto, a referência poderá ser retomada através do uso de diferentes estratégias. As formas de retoma consideradas em Mendes (2013: 1702-1709) são as seguintes:

(a) Retoma por pronomes e pró-formas, caso em que o referente é recuperado por pronomes, pessoais (cf. (8)) ou demonstrativos, ou pró-formas como os determinantes demonstrativos ou alguns advérbios com valor locativo ou temporal (cf. (9)).

(8) $\underline{\text { Jonathan }}_{\mathrm{i}}$ levantou-se e informou Clara ${ }_{\mathrm{j}}$ de que ia tomar um café em frente. Já ele $\underline{\mathrm{e}}_{\mathrm{i}}$ estava a

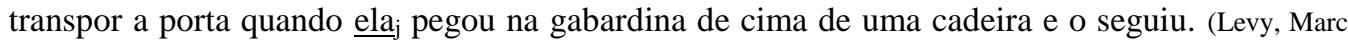
(2005). A Próxima Vez. Cascais: Editora Pergaminho, p.85, trad.)

(9) No final da representação, Jonathan dirigiu-se directamente ao hotel. Ao percorrer as ruas de $\underline{\text { Covent Garden }}_{i}$, pensava na vida que decorria $\underline{\text { ali }}_{i}$ antigamente. (idem, p.74)

(b) Retoma por anáfora fiel ou reiteração, que se verifica através do uso de uma expressão nominal idêntica à expressão com a qual se estabelece o nexo anafórico. Esta estratégia de retoma difere da anterior, no sentido em que, neste caso, as expressões usadas, embora correferentes, são, todas elas, referencialmente independentes.

(10) Jonathan $_{\mathrm{i}}$ olhou Clara $_{\mathrm{j}}$ e sem dizer uma palavra regressou ao trabalho, furioso. Era meio-dia, as lojas da rua estavam fechadas. $\underline{\text { Jonathan }}_{i}$ levantou-se e informou $\underline{\text { Clara }}{ }_{j}$ de que ia tomar um café em frente. (idem)

(c) Retoma por anáfora infiel ou paráfrase, que se concretiza no uso de expressões nominais expandidas para retomar um referente já introduzido no texto, sendo que essas expressões nominais, embora sejam correferentes com a expressão que introduziu o referente, têm uma denotação diferente, uma vez que se centram na descrição de diferentes propriedades dessa mesma entidade. Também neste caso, a expressão nominal usada para a retoma é referencialmente autónoma. A capacidade de o falante estabelecer a relação de correferência entre as expressões que constituem paráfrases e as expressões com as quais estas mantêm uma relação anafórica depende de uma série de conhecimentos, muitos deles de natureza extralinguística, como os conhecimentos sobre o mundo. $\mathrm{O}$ contexto pode também desempenhar um papel importante no reconhecimento da paráfrase.

(11) Atravessaram o grande hall do Dorchester, e $\underline{\text { Peter }}_{i}$ parou diante do balcão do porteiro $j$ para lhe perguntar a direção que deviam tomar para se dirigirem à morada indicada no papel que lhe estendia. O homem vestido de vermelho ${ }_{j}$ deu prontamente a volta ao balcão, desdobrou um mapa do bairro e traçou com uma caneta o itinerário que o hóspede do hotel ${ }_{i}$ deveria tomar para ir à galeria de arte. (idem, p.56)

(d) Retoma por anáfora associativa, estratégia através da qual se estabelece um nexo anafórico que não implica, contrariamente ao que se verifica nos casos anteriores, uma relação de correferência, mas em que a expressão anafórica é referencialmente dependente da expressão antecedente no sentido em que apenas o nexo que estabelece com a expressão antecedente permite fixar a sua referência. 
(12) Clara marcara encontro num pequeno bar no bairro de Notting Hilli, que estava na moda. A luz discreta e a música tornavam o lugar agradável. Ela ainda não chegara e Jonathan decidiu esperála ao balcão . (idem, p.86)

(e) Retoma por anáfora conceptual, caso em que o antecedente da anáfora refere não uma entidade mas uma situação, pelo que a anáfora retoma um conteúdo proposicional apresentado num outro ponto do texto.

(13) No final da décima volta, mais concretamente na curva do castelo, os três primeiros tocaram-se, Luís Lima, que rodava na terceira posição, e Patrik Cunha fizeram um pião, que viria a resultar $\underline{\text { na desistência do segundo }}$. Com este incidente ${ }_{i}$, Pedro Magalhães passou a rodar isolado no comando da corrida, terminando a prova com uma vantagem superior a três segundos. (CRPC, J80277)

\subsection{A distribuição das expressões anafóricas}

A questão da distribuição das anáforas no discurso é complexa, uma vez que envolve o conhecimento de uma série de mecanismos que regulam, por um lado, a produção das anáforas - ou seja, a escolha, por parte de quem produz, das formas anafóricas apropriadas, tendo em conta a interpretação que pretende - e, por outro lado, a sua resolução - ou seja, a identificação, por parte de quem ouve ou lê, do referente das anáforas pretendido num determinado ponto do discurso (Huang, 2000). A vasta literatura sobre esta questão tem apresentado propostas distintas para explicar a distribuição das diferentes formas anafóricas.

Assim, por exemplo, o modelo da continuidade do tópico (topic continuity model), defendido por autores como Givón (1983, 1985, 1990), toma, como ponto de partida para a justificação da utilização de formas anafóricas mais ou menos reduzidas, parâmetros como a distância linear entre as expressões referenciais e a intervenção de outros referentes entre essas expressões. De acordo com esta proposta, se as expressões referenciais se encontrarem próximas e entre elas não intervierem outros referentes, a continuidade do tópico estará assegurada e o falante optará pelo uso de uma forma anafórica mais reduzida: uma expressão nula ou um pronome lexical, por exemplo. Se, pelo contrário, houver uma maior distância entre as expressões ou se se verificar a intervenção de outros referentes em competição, estando, por isso, o tópico mais inacessível, o falante tenderá a optar pelo uso de anáforas mais extensas, nomeadamente, expressões nominais plenas. Huang (2000) mostra, no entanto, que é frequente a ocorrência de expressões nominais plenas em contextos em que a distância entre as expressões é curta e não existe a interferência de outros referentes, assim como é possível a opção por anáforas reduzidas quando o antecedente está distante e se verifica a intervenção de outros potenciais referentes.

Na perspetiva do modelo da hierarquia (hierarchy model), por sua vez, postula-se que é a hierarquia do discurso que condiciona as formas anafóricas selecionadas. A ideia central desta proposta - defendida por Hinds (1978, 1979) e Fox (1987), por exemplo - é a de que a primeira menção a uma entidade ou o início de uma unidade estrutural do discurso implicam o uso de uma expressão nominal plena, enquanto as menções subsequentes que ocorrem no interior da mesma unidade textual (um parágrafo, um episódio, um tema, etc.) tendem a ser instanciadas por expressões anafóricas. Desta forma, estabelece-se uma relação direta entre a organização do discurso e a seleção das expressões referenciais.

Grosz, Joshi \& Weinstein (1995), no seu modelo de centralização (centering theory), propõem que, num enunciado, certas entidades são mais centrais do que outras e que este aspeto condiciona a seleção das formas anafóricas. Os autores salientam a propriedade da coerência, ao nível das sequências textuais individuais e ao nível de todo o discurso, como um fator que determina a ocorrência de diferentes tipos de expressões referenciais, as quais vão originar diferentes inferências no ouvinte ou leitor.

Existem, no entanto, modelos que sublinham a importância de fatores de natureza cognitiva, como a ativação e a atenção, para a codificação anafórica. Trata-se de modelos cognitivos (cognitive model), como o 
desenvolvido, por exemplo, por Lambrecht (1994) e Gundel, Hedberg \& Zacharski (1993). Neste contexto, o termo "ativação" designa o resultado da focalização da atenção num referente na memória de curto prazo. De acordo com esta hipótese, torna-se previsível a ocorrência de uma expressão nominal plena quando o referente não está ativado, enquanto as formas anafóricas mais reduzidas são reservadas para os contextos em que os referentes estão ativados. Considerando uma escala ou hierarquia de estados cognitivos, os defensores desta perspetiva relacionam estados cognitivos relativos ao referente (como, por exemplo: focalizado, ativado, familiar, identificável como único, referencial, identificável como tipo - cf. Gundel, Hedberg \& Zacharski,1993) com a ocorrência de diferentes tipos de expressões referenciais. Assim, o estado "focalizado", por exemplo, corresponde ao uso de uma expressão com um mínimo de (ou nenhum) conteúdo fonológico, ou seja, a um pronome lexical ou nulo, uma vez que corresponde a um estado em que o referente já está suficientemente restringido. Pelo contrário, o estado "identificável como tipo" conduz ao uso de uma expressão nominal plena, de forma a obter-se uma maior restrição do referente. Alguns adeptos desta perspetiva têm desenvolvido estudos experimentais na área da psicolinguística que corroboram esta relação.

$\mathrm{Na}$ verdade, as conclusões a que se chega a partir do modelo cognitivo são semelhantes àquelas que resultam de outras perspetivas, como as mencionadas atrás. Assim, conclui-se que, por exemplo, numa narração, os falantes tendem a utilizar expressões nominais plenas no início de cada episódio, mas usam mais frequentemente formas reduzidas (nulas ou lexicais) no interior de cada episódio. Da mesma forma, quando um episódio está organizado em secções, existe uma tendência para a utilização de expressões nominais plenas no início de cada secção e para o uso de formas reduzidas no interior dessa secção. Huang (2000) faz, no entanto, notar que nem sempre esta relação se verifica, dado que, por exemplo, os falantes usam, por vezes, expressões nominais plenas mesmo quando os referentes estão ativados.

Também Ariel (1996) desenvolve uma teoria sobre a distribuição das anáforas que se baseia na relação que se estabelece entre a forma das anáforas e a proeminência do antecedente, estabelecendo uma escala escala de marcação de acessibilidade (accessibility marking scale) - que correlaciona estes dois fatores: quanto mais acessível estiver o antecedente, mais reduzida será a forma anafórica utilizada. Assim, a ocorrência de anáforas nulas adequa-se a contextos em que o referente está muito acessível, enquanto as expressões nominais plenas são favorecidas por contextos em que o referente está pouco acessível.

Alguns trabalhos procuram ainda explicar o uso das expressões referenciais propondo a existência de uma relação entre a distribuição das anáforas e aspetos de natureza pragmática. São exemplo do modelo pragmático (pragmatic model) vários trabalhos de Huang, como o de 1989 e o de 2000, um pouco na linha dos princípios conversacionais de Grice (1989). Assim, Huang (2000: 164-165) formula as seguintes convenções pragmáticas:

(14) A. O estabelecimento da referência tende a ser produzido por expressões nominais expandidas.

B. A mudança da referência tende a ser produzida por expressões nominais expandidas.

C. A manutenção da referência tende a ser produzida por pronomes nulos ou plenos.

De acordo com o autor, estes padrões articulam-se com as estratégias pragmáticas propostas por Levinson (1991, 1995), nomeadamente:

(15) A. Não dizer menos do que o requerido. $\rightarrow$ Dizer o necessário para que haja reconhecimento.

B. Não dizer mais do que o requerido $\rightarrow$ Dizer o mínimo necessário para que haja minimização.

Nesta perspetiva, as expressões nominais expandidas são usadas apenas quando a sua presença é necessária para o reconhecimento do referente, e, quando tal não é necessário, opta-se pela minimização, usando-se expressões mínimas, como os pronomes com realização lexical ou nulos. 


\subsection{O estabelecimento da referência de expressões dependentes}

\subsubsection{Condições discursivas ou pragmáticas: o papel das inferências}

Como foi notado por Levinson (1987), o estabelecimento da referência de expressões nominais dependentes resulta, muitas vezes, de um mecanismo de inferência por parte do leitor do texto, sendo a não realização lexical da expressão favorecida em contextos em que o referente já foi apresentado, ou seja, em que é partilhado por um antecedente. Assim, em (16a), a omissão do sujeito obriga à procura de um nexo anafórico que permita o estabelecimento da referência, pelo que o sujeito nulo é obrigatoriamente correferente com a expressão o Pedro. Contrariamente, em (16b) e (16c), as expressões ele e o rapaz são interpretadas preferencialmente como correferentes com a expressão o Pedro, mas esta correferência não existe necessariamente.

(16) a. $O P e d r o_{\mathrm{i}}$ é muito independente, mas [- $]_{\mathrm{i}}$ não vive sem a Maria.

b. $O P e d r o_{\mathrm{i}}$ é muito independente, mas el $_{\mathrm{i} / \mathrm{j}}$ não vive sem a Maria.

c. $O P e d r o_{\mathrm{i}}$ é muito independente, mas $o$ rapaz $_{\mathrm{i} / \mathrm{j}}$ não vive sem a Maria.

Com efeito, a inferência de correferência ou não depende, nestes casos, de fatores linguísticos e extralinguísticos que se prendem com aspetos como o conteúdo das proposições envolvidas ou mesmo com os conhecimentos pragmáticos, sobre o mundo. Assim, por exemplo, em (17), as mesmas expressões não serão consideradas preferencialmente correferentes com a expressão $o$ Pedro:

(17) a. $O P e d r o_{\mathrm{i}}$ é muito independente, mas $e l e_{\mathrm{j}}$ não aceita essa independência.

b. $O P e d r o_{i}$ é muito independente, mas $o$ rapazj não aceita essa independência.

O mesmo fenómeno acontece quando as expressões ocorrem em unidades estruturais diferentes, por exemplo, em períodos de texto diferentes. Vejam-se os exemplos em (18) e (19), em que as relações referenciais que se estabelecem entre as expressões referenciais envolvidas são as mesmas observadas, respetivamente, em (16) e (17):

(18) a. $O P e d r o_{1}$ é muito independente. No entanto, $[-]_{\mathrm{i}}$ não vive sem a Maria.

b. $O$ Pedro ${ }_{\mathrm{i}}$ é muito independente. No entanto, el $_{\mathrm{i}}$ não vive sem a Maria.

c. $O P e d r o_{1}$ é muito independente. No entanto, o rapazi não vive sem a Maria.

(19) a. $O P e d r o_{\mathrm{i}}$ é muito independente. No entanto, $e l e_{\mathrm{j}}$ não aceita essa independência.

b. $O P e d r o$ í muito independente. No entanto, o rapazj não aceita essa independência.

Existem, então, contextos que favorecem a inferência de correferência, muitas vezes em função do conteúdo das proposições envolvidas no texto e tendo em conta aspetos extralinguísticos como o conhecimento do mundo. Esta situação verifica-se de forma muito clara nos exemplos de (20), em que o pronome que ocorre no segundo período é interpretado em função do conteúdo da frase que corresponde ao período anterior: assim, em (20a), o pronome será preferencialmente interpretado como correferente com a expressão $o$ Pedro, enquanto em (20b), o mesmo pronome será preferencialmente considerado correferente com o João. A preferência pelas relações de correferência descritas deve-se ao nosso conhecimento extralinguístico de que, provavelmente, se a entidade X é a entidade que sente paixão pela Maria, então, será a entidade X que tem um entusiasmo notório pela Maria. 
(20) a. $O P e d r o_{\mathrm{i}}$ confessou ao João $\mathrm{j}_{\mathrm{j}}$ sua paixão pela Maria. De resto, era notório o entusiasmo que $e l e_{\mathrm{i}}$ tinha pela rapariga.

b. O Pedro ${ }_{i}$ percebeu a paixão do João $o_{\mathrm{j}}$ pela Maria. De resto, era notório o entusiasmo que el $_{\mathrm{j}}$ tinha pela rapariga.

Em qualquer dos casos, em (20), a interpretação referencial do pronome pessoal é, no entanto, potencialmente ambígua. Esta ambiguidade poderia ser eliminada usando uma estratégia diferente de retoma do referente, como acontece em (21), em que a retoma se verifica pela utilização de pronomes demonstrativos, cuja forma induz, na interpretação anafórica, uma maior distância ou proximidade do antecedente, obrigando a que a correferência se estabeleça, em (21a), com a expressão o Pedro (o mais distante dos seus potenciais antecedentes) e, em (21b), com a expressão o João (o mais próximo dos seus potenciais antecedentes):

(21) a. $O$ Pedro $_{\mathrm{i}}$ confessou ao João a sua paixão pela Maria. De resto, era notório o entusiasmo que aquele $e_{\mathrm{i}}$ tinha pela rapariga.

b. O Pedro ${ }_{i}$ percebeu a paixão do João $o_{\mathrm{j}}$ pela Maria. De resto, era notório o entusiasmo que $e{ } e_{\mathrm{j}}$ tinha pela rapariga.

Por outro lado, há contextos que desfavorecem a interpretação de correferência, existindo mesmo casos que eliminam essa possibilidade. É o que se verifica em (22), em que, apesar de o conteúdo das proposições permitir o estabelecimento de uma relação de correferência entre o pronome ele e a expressão nominal $o$ Pedro, esta não se verifica por razões que podem ser consideradas gramaticais, como discutiremos adiante: ${ }^{6}$

(22) a. $O P e d r o_{\mathrm{i}}$ disse que ama a Maria e ele $_{*_{\mathrm{i}} / \mathrm{j}}$ mostrou-se entusiasmado pela rapariga.

b. $O P e d r o_{\mathrm{i}}$ disse que ele $_{*_{\mathrm{i} / \mathrm{j}}}$ ama a rapariga.

c. $O$ Pedro $_{\mathrm{i}}$ imagina que ele $_{*_{\mathrm{i}} / \mathrm{j}}$ ame a Maria.

\subsubsection{Restrições gramaticais: a questão do sujeito nulo}

Embora as relações de referência apresentadas nas secções anteriores sejam, na generalidade, comuns às várias línguas, os meios linguísticos para as estabelecer podem variar. Um dos contextos em que existe maior variação diz respeito ao sujeito e ao tipo de categorias que podem ocupar tal posição em frases finitas. Assim, por exemplo, uma língua como o português usa tipicamente descrições indefinidas para introduzir um referente (cf. (23)), podendo as retomas seguintes, também em posição de sujeito, ser concretizadas através de uma descrição definida (cf. (24)) ou de uma forma pronominal (cf. (25)). Esta estratégia coincide aliás com o que é proposto por autores como Hinds (1978, 1979), Fox (1987) ou Huang (1989, 2000) - cf. Secção 2.3.

(23) Era uma vez uma princesa.

(24) a. A princesa vivia num palácio na montanha.

b. Esta princesa vivia num palácio na montanha.

c. A menina vivia num palácio na montanha.

\footnotetext{
${ }^{6}$ Como um dos revisores assinalou, nas frases (22a) e (22b), a leitura de correferência entre o sujeito pronominal encaixado e o sujeito matriz, não sendo a interpretação preferida, não é impossível. No entanto, parece-nos que esta leitura só é possível se o sujeito pronominal for interpretado contrastivamente, ou seja, se o seu referente for interpretado por oposição a todas as outras entidades do mundo de referência, caso em que o pronome recebe acento enfático.
} 
(25) a. Ela vivia num palácio na montanha.

b. [-] Vivia num palácio na montanha.

Em (23), estamos perante um contexto apresentacional, que permite introduzir, através da descrição indefinida, uma princesa, um novo referente no discurso. Em (24), este referente é retomado na posição de sujeito por descrições definidas, através de um processo de anáfora fiel (24a, b) ou de anáfora infiel (24c). Neste mesmo contexto, em português, a retoma pode ser feita através de uma forma pronominal com realização lexical, ela em (25a), ou por uma forma pronominal nula, como em (25b).

Se considerarmos dados do inglês equivalentes aos apresentados em (23)-(25), verificamos que as estratégias usadas para a construção da cadeia referencial são as mesmas, distinguindo-se as duas línguas pelas formas linguísticas disponíveis para concretizar tais estratégias. Com efeito, comparando os dados do inglês com os do português, pode-se concluir que ambas as línguas admitem retomas por anáfora, fiel (cf. (24a, b) e $(27 \mathrm{a}, \mathrm{b})$ ) ou infiel (cf. (24c) e (27c)), ou por formas pronominais (cf. (25a) e (28a)), mas apenas o português admite uma forma pronominal nula em posição de sujeito de uma frase finita (cf. (25b) e (28b)).

(26) Once upon a time there was a princess.

(27) a. The princess lived in a castle on the hill.

b. This princess lived in a castle on the hill.

c. The girl lived in a castle on the hill.

(28) a. She lived in a castle on the hill.

b. *[-] lived in a castle on the hill.

A diferença entre as línguas a este respeito, em particular no que concerne à possibilidade de ocorrência de um sujeito nulo em frases finitas, tem sido amplamente explorada em vários estudos desde a década de 1970 (por exemplo, Perlmutter, 1971; Kayne, 1980; Chomsky, 1982; Rizzi, 1982, 1986; Barbosa, 1995, 2018, entre outros), tendo sido formalmente estabelecida através do conhecido Parâmetro do Sujeito Nulo (Rizzi, 1982), recentemente repensado em trabalhos como Holmberg (2005), Holmberg (2010), Roberts (2010), Roberts \& Holmberg (2010), d'Alessandro (2014), entre outros. Tais estudos têm tido impacto direto na análise comparada entre línguas, uma vez que o seu objetivo último tem sido o de estabelecer as propriedades das gramáticas dessas línguas, pelo que, indiretamente, fornecem informação crucial para a adoção de estratégias de adaptação inerentes ao processo de tradução quando as línguas do par em causa são tipologicamente distintas.

Em inglês, língua de partida das traduções analisadas na Secção 3, todas as ocorrências de sujeito nulo são agramaticais em contextos finitos. Por sua vez, o português europeu (PE), língua de chegada das mesmas traduções, é uma língua de sujeito nulo consistente. No entanto, nesta língua, a realização ou a omissão do sujeito podem ser obrigatórias ou por razões de natureza pragmático-discursiva, como se mostrou nas secções anteriores, ou por razões de natureza gramatical. ${ }^{7}$ Em ambas as situações, a opção por omitir ou por realizar o sujeito tem, geralmente, impacto sobre a identificação do seu referente .

$\mathrm{O} \mathrm{PE}$ exibe um contraste claro no que diz respeito à possibilidade de sujeitos nulos em função da pessoa gramatical. Como é sabido, esta língua dispõe de um sistema flexional verbal rico, que, no caso das 1 . $^{\mathrm{a}}$ e 2 . $^{\mathrm{a}}$ pessoas, permite, na generalidade, a identificação do referente como o locutor e o interlocutor, respetivamente. Como anteriormente se afirmou, trata-se de formas pronominais que correspondem a elementos dêiticos, sendo, portanto, o seu referente recuperado no próprio contexto de enunciação. Neste caso, sujeitos de $1 .^{a}$ e $2 .^{a}$ pessoas são preferencialmente nulos em frases raiz (29), em subordinadas (30) e em coordenadas (31), em conformidade

${ }^{7}$ Seguiremos, no essencial, a descrição do PE em Lobo (2013a, 2013b) e a análise comparada entre PE e PB em Duarte \& Figueiredo Silva (2016). Remetemos para as autoras, para uma descrição minuciosa dos sujeitos nulos em PE. 
com o Princípio Evite o Pronome (Avoid Pronoun Principle, de Chomsky, 1981) ou o princípio Minimize a Estrutura (Minimize Structure, de Cardinaletti \& Starke, 1999):

(29) [-] Comi um bolo.

(30) a. A Maria disse que [-] fiz um bom trabalho.

b. O professor deu-me uma boa classificação porque [-] fiz um bom trabalho.

c. $[-]_{\mathrm{i}}$ Acho que $[-]_{\mathrm{i}}$ fiz um bom trabalho.

(31) a. [-] Escrevi um poema e o Pedro leu-o na aula.

b. $[-]_{\mathrm{i}}$ Escrevi um poema e $[-]_{\mathrm{i}}$ li-o na aula.

Nos exemplos (29), (30a), (30b) e (31a), a forma nula do pronome pode alternar com a forma realizada, cf. (32)-(34); já em (30c) e (31b), a realização da forma pronominal nas duas posições dá origem a redundância, que tende a ser evitada pelos falantes, a não ser que se pretenda atribuir uma leitura de contraste ao sujeito, (35) - ver nota 6:

(32) $E u$ comi um bolo.

(33) a. A Maria disse que eu fiz um bom trabalho.

b. O professor deu-me uma boa classificação porque $e u$ fiz um bom trabalho.

(34) Eu escrevi um poema e o Pedro leu-o na aula.

(35) a. \#Eu acho que eu fiz um bom trabalho. / Eu acho que EU fiz um bom trabalho; quanto a ti, não sei...

b. \#Еu escrevi um poema e eu li-o na aula. / Eu escrevi um poema e EU li-o na aula; tu não fizeste nada.

Note-se que, em (35), o falante pode optar por realizar apenas o primeiro sujeito sem que se registe uma leitura contrastiva.

(36) a. $E u_{\mathrm{i}}$ acho que $[-]_{\mathrm{i}}$ fiz um bom trabalho.

b. $E u_{\mathrm{i}}$ escrevi um poema e $[-]_{\mathrm{i}}$ li-o na aula.

Embora os sujeitos nulos de $1 .^{\mathrm{a}}$ e $2 .^{\mathrm{a}}$ pessoas sejam admitidos na generalidade dos contextos, algumas estruturas sintáticas obrigam à sua realização. É o que acontece quando o sujeito é focalizado contrastivamente (Lobo, 2013b: 2332-2333), em exemplos como os que se seguem:

(37) a. Foste $t u$ que me disseste para sair.

b. *Foste [-] que me disseste para sair.

c. Tu é que me disseste para sair.

d. *[-] é que me disseste para sair

(38) a. Até eu sei fazer essa conta.

b. \#Até [-] sei fazer essa conta. (\# na leitura pretendida)

(39) A: Limpa o vidro.

B. Limpa $t u$ !

B': *Limpa [-]!

(40) a. Na terça-feira chega o Pedro e na quarta chegamos nós.

b. * Na terça-feira chega o Pedro e na quarta chegamos [-]. 
É também o que acontece quando a forma de $1 .^{\mathrm{a}}$ pessoa é homófona da de 3 . $^{\mathrm{a}}$ pessoa, o que impede a identificação correta do referente (41). Neste caso, terão de ser tidos em conta o contexto linguístico anterior (cf. (42)) e/ou o contexto situacional.

(41) [-] Dava um presente à Maria, se [-] tivesse dinheiro.

(42) a. [- $]_{\mathrm{i}}$ Gosto muito da Maria. [- $]_{\mathrm{i}}$ Dava -lhe um presente, se [- $]_{\mathrm{i}}$ tivesse dinheiro.

b. $O P e d r o_{\mathrm{i}}$ gosta muito da Maria. [- $]_{\mathrm{i}}$ Dava -lhe um presente, se $[-]_{\mathrm{i}}$ tivesse dinheiro.

Note-se, porém, que a ocorrência de clíticos com traços de pessoa e número permite eliminar a ambiguidade, sem recurso ao contexto, permitindo a identificação correta dos referentes dos dois sujeitos nulos:

(43) a. [- $]_{1 \mathrm{SG}}$ Disfarçava-me ${ }_{1 \mathrm{SG}}$ de detetive, se $[-]_{1 \mathrm{SG}}$ tivesse de ir a um baile de máscaras.

b. [- $]_{3 S G}$ Disfarçava-se $3 S G$ de detetive, se $[-]_{3 S G}$ tivesse de ir a um baile de máscaras.

Relativamente à $3 .^{a}$ pessoa, sujeitos expletivos são obrigatoriamente nulos na variedade padrão do PE: ${ }^{8}$

(44) a. [-] Vai chover.

b. [-] Há muitas ideias erradas no futebol.

Também são legítimos sujeitos nulos de 3. pessoa com referência arbitrária:

$$
\text { [-] Partiram os vidros dos carros. }
$$

Neste caso, a opção por sujeito nulo ou por sujeito realizado é crucial para a interpretação. Com efeito, se, em frases como (45), o sujeito nulo designa uma entidade indefinida, não conhecendo o locutor o seu referente, em (46), o pronome designa obrigatoriamente uma entidade específica (por exemplo, os assaltantes), devendo o seu referente ser identificado ou pelo contexto linguístico anterior ou pelo contexto situacional.

Eles partiram os vidros dos carros.

Quanto aos sujeitos nulos referenciais de $3 .^{\mathrm{a}}$ pessoa, sem contexto anterior, não são legítimos nas frases raiz do $\mathrm{PE}$, dada a impossibilidade de recuperar a sua referência no conjunto de múltiplas entidades que pode referir (cf. (47) vs. (48), em que existe um tópico saliente num par pergunta-resposta).

(47) \#[-] Comeu um bolo.

(48) A: E o Pedro $i$, o que é que fez?

B: $[-]_{\mathrm{i}}$ Comeu um bolo.

\footnotetext{
${ }^{8}$ Variedades não padrão, contudo, admitem o preenchimento da posição de sujeito por uma forma pronominal nominativa invariável, ele em contextos impessoais, com diversos tipos de predicados (Carrilho 2005, 2008):

(i) $\mathrm{Ah}$, se chover era melhor, mas ele não chove amanhã. (Carrilho 2008: 14) Vejam-se, ainda, exemplos retirados de obras literárias como os de (ii) e (iii), apresentados em Carrilho (2008: 10):

(ii) Afinal o que importa não é ser novo e galante / ele há tanta maneira de compor uma estante! (Mário Cesariny)

(iii) Elas acudiam com números de telefone: ele era para a ama que tinha ficado com o filho, ele era para a mãe, ele era «para uma grande amiga que é como se fosse minha irmã». (Alçada Baptista)
} 
Também no caso de frases coordenadas, apenas podem ocorrer sujeitos nulos de 3 . $^{\mathrm{a}}$ pessoa no primeiro membro da coordenação se a sua referência for recuperável no contexto anterior (cf. (49a) vs. (49b)); podem ocorrer nos restantes membros da coordenação, obtendo-se, neste caso, uma leitura de correferência entre sujeitos (cf. (50)):

(49) a. [- $]_{* \mathrm{i} / \# \mathrm{j} j}$ Escreveu um poema e o Pedro $\mathrm{P}_{\mathrm{i}}$ leu-o na aula.

b. (Sabes o que fez $o$ João $o_{\mathrm{j}}$ ? ) [-] $*_{\mathrm{i} / \mathrm{j}}$ Escreveu um poema e $o$ Pedro $o_{\mathrm{i}}$ leu-o na aula.

(50) a. O Pedro $\mathrm{i}_{\mathrm{i}}$ escreveu um poema e $[-]_{\mathrm{i} /{ }^{\mathrm{j}}}$ leu-o na aula.

b. (Sabes o que fez o Pedro $_{i}$ ?) $[-]_{\mathrm{i}}$ Escreveu um poema e $[-]_{\mathrm{i}}$ leu-o na aula.

Se o sujeito for realizado, a inferência de correferência ou de referência disjunta depende, como se disse anteriormente, de fatores linguísticos e extralinguísticos. Vejam-se os exemplos (16b) e (17a), repetidos em (51) e (52), bem como (53), em que a relação de correferência se estabelece entre o sujeito do segundo membro da coordenação e um constituinte que ocorre no interior do sujeito do primeiro membro ou um objeto:

(51) $O P$ Pedro $o_{\mathrm{i}}$ é muito independente, mas $e l e_{\mathrm{i} / \mathrm{j}}$ não vive sem a Maria.

(52) $O$ Pedro $_{\mathrm{i}}$ é muito independente, mas ele $*_{\mathrm{i} / \mathrm{j}}$ não aceita essa independência.

(53) a. [O amigo do Rui $]_{\mathrm{j}}$ i comeu um bolo e ele $*_{\mathrm{i} / \mathrm{j} / \mathrm{k}}$ bebeu uma água.

b. $O R u i_{\mathrm{i}}$ viu $o$ Pedro $_{\mathrm{j}}$ e ele $_{*_{\mathrm{i}} / \mathrm{j}}$ abraçou-o efusivamente.

c. $O R_{u i}$ nunca obedece ao pai $_{\mathrm{j}}$ e $e l e_{*_{\mathrm{i}} / \mathrm{j}}$ irrita-se.

Em estruturas de subordinação, são possíveis formas nulas de $3 .^{a}$ pessoa a par de formas realizadas, mas a opção por um sujeito nulo ou por um sujeito realizado tem impacto na interpretação. Em geral, as formas nulas admitem mais facilmente uma interpretação anafórica (Brito, 1991; Lobo, 2013a) e as formas realizadas estão primordialmente associadas a leituras não correferenciais (efeito de obviação referencial); esta generalização verifica-se com subordinadas completivas (cf. (54)) e adverbiais (cf. (55)) de indicativo:

(54) a. $O P e d r o_{\mathrm{i}}$ considera que $[-]_{\mathrm{i}}$ fez um bom trabalho.

b. $O$ Pedro $o_{\text {i }}$ considera que $e l e *_{\mathrm{i} / \mathrm{j}}$ fez um bom trabalho.

(55) a. Quando $[-]_{\mathrm{i}}$ acabou o trabalho, o Pedro $o_{\mathrm{i}}$ saiu rapidamente.

b. Quando ele $*_{\mathrm{i} / \mathrm{j}}$ acabou o trabalho, o Pedro $\mathrm{i}_{\mathrm{i}}$ saiu rapidamente. ${ }^{9}$

Note-se, porém, que, se o sujeito da encaixada tiver um valor de foco contrastivo, a sua realização com leitura de correferência passa a ser possível, como nos casos em que se realizam sujeitos de 1 . $^{\mathrm{a}}$ e 2 . $^{\mathrm{a}}$ pessoas:

(56) $O P e d r o_{\text {i }}$ considera que $E L E_{\mathrm{i}}$ fez um bom trabalho. (O Pedro não sabe se outras pessoas fizeram um bom trabalho)

Nos contextos de subordinação, podem ainda ocorrer sujeitos realizados cujo antecedente se encontra no interior da frase complexa, em posições mais baixas do que o sujeito (cf. (57) e (58)) ou em posição de tópico associado à oração matriz (cf. (59) - construção de tópico pendente):

\footnotetext{
${ }^{9}$ Num estudo sobre interpretação de pronomes em orações adverbiais do PE, Lobo \& Silva (2016) mostram que, mesmo em contextos ambíguos, ou seja, em que há dois possíveis antecedentes para o pronome (cf. (i)), os adultos só selecionam o sujeito matriz como antecedente do sujeito pleno catafórico em $39 \%$ dos casos. Nos restantes $61 \%$ dos casos, é selecionado o objeto como antecedente. (i) Quando ela saiu da garagem, a bruxa molhou a princesa. (Lobo \& Silva, 2016:327)
} 
(57) a. [O amigo d[or $\left.R u i]_{\mathrm{j}}\right]_{\mathrm{i}}$ reparou que $e e_{*_{\mathrm{i}} / \mathrm{j}}$ estava a conduzir muito depressa

b. [ [ $O$ amigo $\left.d\left[\begin{array}{ll}o & R u i\end{array}\right]_{\mathrm{j}}\right]_{\mathrm{i}}$ reparou que $[-]_{\mathrm{i} / *_{\mathrm{j}}}$ estava a conduzir muito depressa.

(58) $O Z e_{i}$ perguntou ao Pedro $o_{\mathrm{j}}$ se ele $_{\# \mathrm{i} / \mathrm{j} / \mathrm{k}}$ apreciava viagens de comboio. ${ }^{10}$

(59) $O Z e_{\mathrm{i}}$, o Miguel $_{\mathrm{j}}$ disse que $e l e_{\mathrm{i} / *_{\mathrm{j}} / *_{\mathrm{k}}}$ não suporta corruptos.

É interessante notar que, nos dados de (57) a (59), a opção por realizar ou omitir o sujeito só tem impacto na interpretação em (57); nos restantes casos, a omissão do sujeito induz necessariamente a leitura de correferência que se observa também quando o sujeito é realizado (comparem-se (58)-(59) com (60)-(61)).

(60) $O Z e_{i}$ perguntou ao Pedro $o_{\mathrm{j}}$ se $[-]_{\mathrm{*}_{\mathrm{i}} / \mathrm{j} / \mathrm{k}}$ apreciava viagens de comboio.

(61) $O Z e_{\text {i }}$, o Miguel $_{\mathrm{j}}$ disse que $[-]_{\mathrm{i} / *_{\mathrm{j}} / * \mathrm{k}}$ não suporta corruptos.

Em contextos de complementação com conjuntivo, as formas nulas de sujeito não são, na generalidade, compatíveis com uma leitura de correferência (cf. (62)), ao contrário do que acontece com os contextos de indicativo. Assim, em (63), o antecedente do pronome nulo encontra-se externamente à frase complexa.

(62) $O Z e_{\text {i }}$ quer que $[-] *_{\mathrm{i} / \mathrm{j}}$ acabe o trabalho até amanhã.

(63) $\quad[-]_{\mathrm{i}}$ Falei com a Maria $\mathrm{j}_{\mathrm{j}}[-]_{\mathrm{i}}$ Quero que $[-]_{\mathrm{j}}$ acabe o trabalho até amanhã.

Sendo (62) o exemplo do que acontece tipicamente em contextos de complementação com conjuntivo, registam-se, no entanto, algumas ocorrências de sujeitos nulos correferentes com o sujeito da oração matriz, dependendo da classe do verbo desta oração (64) e/ou do verbo encaixado (65):

(64) a. $[-]_{\mathrm{i}}$ Espero que $[-]_{\mathrm{i} / \mathrm{j}}$ chegue a tempo.

b. Ele $e_{\mathrm{i}}\{$ receia / teme $\}$ que $[-]_{\mathrm{i} / \mathrm{j}}$ não consiga ver o filme.

c. $[-]_{\mathrm{i}}$ Duvido que $[-]_{\mathrm{i} / \mathrm{j}}$ acabe o trabalho no prazo.

(exs. de Marques, 2018: 225)

(65) a. $O R u i_{\text {i lamenta que }[-] *_{i} / j}$ não convide esses amigos.

b. $O R u i_{\mathrm{i}}$ lamenta que $[-]_{\mathrm{i} / \mathrm{j}}$ não possa convidar esses amigos.

c. $O R u i_{\mathrm{i}}$ lamenta que $[-]_{\mathrm{i} / \mathrm{j}}$ tenha feito tantos erros.

(exs. de Lobo, 2013a: 2202)

Também são admitidos sujeitos nulos correferentes com o sujeito matriz em completivas de verbos que selecionam indicativo em frases afirmativas, mas conjuntivo na presença de advérbios de negação frásica:

(66) a. $O R u i_{\text {i }}$ acha que $[-]_{\mathrm{i}}$ é muito alto.

b. $O R u i_{\mathrm{i}}$ não acha que $[-]_{\mathrm{i}}$ seja muito alto.

(exs. de Lobo, 2013a:2204)

Assim, em contextos de complementação com conjuntivo, as formas realizadas em posição de sujeito da encaixada estão associadas a leituras obviativas (compare-se (66b) com (67b)), ou seja, não podem ter uma leitura correferencial com o sujeito:

(67) a. O Zé $e_{i}$ quer que ele $*_{i / j}$ acabe o trabalho até amanhã.

\footnotetext{
${ }^{10}$ Como assinalou um dos revisores, é possível obter-se uma interpretação de correferência em determinados contextos legitimados pragmaticamente:
}

(i) $O Z e_{i}$ perguntou ao $p a i_{\mathrm{j}}$ se $e l e_{\mathrm{i} / \mathrm{j} / \mathrm{k}}$ apreciava viagens de comboio quando era criança. 
b. O Rui $i_{\mathrm{i}}$ não acha que ele $*_{\mathrm{i} / \mathrm{j}}$ seja muito alto.

Em certos contextos de subordinação adverbial com conjuntivo, observam-se duas situações (Lobo, 2013a: 2205): (i) quando o sujeito da encaixada é realizado, é mais natural a leitura em que os sujeitos têm uma referência disjunta (cf. (68a)); (ii) quando o sujeito da encaixada é nulo, é mais natural a leitura de correferência entre os sujeitos $(68 b)$.

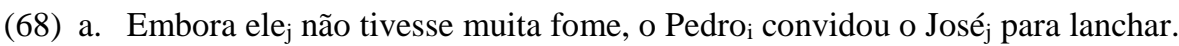

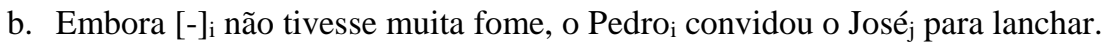

\section{Dados da tradução inglês-português em contexto académico}

A tradução no contexto em que as línguas de trabalho são diferentes no que diz respeito ao preenchimento lexical do sujeito implica alterações ao nível da construção das cadeias de referência. Assim, a manutenção, no texto traduzido, das relações anafóricas que se estabelecem entre as expressões referenciais no texto de partida pode implicar um exercício de adaptação que resulta, muitas vezes, na seleção de formas anafóricas diferentes.

$\mathrm{O}$ conhecimento das propriedades das línguas de trabalho relativamente à possibilidade de ocorrência de sujeitos nulos e, no caso de admitirem sujeitos nulos, à natureza desses mesmo sujeitos é crucial para quem trabalha na área da tradução. Na situação concreta da tradução de inglês para português, o tradutor deve ser capaz de reconhecer os contextos em que, em português, pode omitir o sujeito sem afetar a interpretação e sem criar vagueza, conflito ou ambiguidade referencial. Adicionalmente, deve ser capaz de identificar os contextos em que tem de omitir o sujeito, de acordo com princípios linguísticos relacionados com máximas que regulam a interação verbal, como o Princípio Evite o Pronome ou o princípio Minimize a Estrutura.

A experiência dos professores que trabalham no domínio da tradução no ensino universitário revela que os estudantes apresentam frequentemente problemas relacionados com a coesão textual ${ }^{11}$, nomeadamente com a manutenção das cadeias de referência, sobretudo quando as línguas de trabalho são distintas quanto à possibilidade de essas cadeias incluírem formas pronominais nulas. Nesta secção do trabalho, pretende-se apresentar dados produzidos por estudantes universitários, a fim de ilustrar os principais problemas que decorrem de diferentes propriedades das línguas no que diz respeito aos sujeitos nulos. Trata-se de um estudo exploratório, para o qual foram considerados 7 textos (5 narrativos e 2 expositivos) traduzidos, sem correções pelo docente; cada texto tinha uma extensão de cerca de 2000 palavras. Os estudantes frequentavam o $1 .^{\circ}$ ano do mestrado em Tradução da Faculdade de Letras da Universidade de Lisboa e eram falantes nativos de PE. Para o presente trabalho, foram recolhidos todos os excertos em que foram identificados problemas relacionados com cadeias referenciais que envolvessem posições de sujeito.

\section{A. Casos em que a opção por uma forma anafórica nula impede o reconhecimento do referente pretendido}

\section{(i) Ocorrência de sujeito nulo com formas verbais que não permitem identificar o sujeito}

Considere-se o exemplo (69):

\footnotetext{
${ }^{11}$ A existência de dificuldades de escrita ao nível da coesão textual por parte de estudantes universitários portugueses já foi notada por outros autores. Veja-se, por exemplo, o trabalho de Cardoso \& Magro (2013), em que se apresentam dados de corpora retirados de textos académicos que atestam dificuldades dos estudantes universitários relacionadas com a coesão referencial quando escrevem textos na sua língua materna.
} 
(69) a. - Mãe. - Ajoelhei-me perante ela, já que era assim que [-] gostava, usando um tom de respeito. b. 'Mother.' I knelt before her, since that was the way she liked it, making my voice respectful.

Em (69), a forma verbal gostava é idêntica para a $1^{\mathrm{a}}$ e a $3^{\mathrm{a}}$ pessoa. A opção por um sujeito nulo na subordinada torna possível uma leitura de correferência com o sujeito da matriz. Trata-se de uma ambiguidade introduzida na tradução, já que o pronome realizado de $3^{\mathrm{a}}$ pessoa do texto de partida foi substituído, no texto de chegada, por um pronome nulo.

O exemplo (70) corresponde a uma ocorrência de um sujeito nulo referencial de $3^{\mathrm{a}}$ pessoa cuja referência pode ser recuperada por mais do que um potencial antecedente:

(70) a. Mais que na maioria dos designers, as coleções do Kane percepcionam-se sempre profundamente pessoais, por isso era inevitável que os críticos ligassem o tema de 'a Criação que vem da Destruição' do 'Colidir e Consertar' à perda da sua mãe, Christine, que faleceu três dias antes do desfile e no mesmo dia em que [-] abriu a sua primeira loja em Londres, em 2015.

b. More than most designers, Kane's collections always feel deeply personal, so it was inevitable that critics would link Crash and Repair's "creation coming from destruction" theme to the loss of his mother, Christine, who died three days before the show and on the same day that he opened his first London store in 2015.

Note-se que o sujeito nulo que ocorre associado à forma verbal de $3^{\mathrm{a}}$ pessoa do singular abriu não permite o reconhecimento do referente, uma vez que a relação anafórica se estabelece com uma expressão nominal mais próxima, a sua mãe, Christine, que intervém entre os elos da cadeia, e não com o referente pretendido que, como se pode confirmar através do excerto de partida, é fixado pela expressão o Kane. Como no exemplo anterior, também aqui o problema foi introduzido na tradução, já que o pronome realizado, na língua de partida, com forma masculina foi substituído, na língua de chegada, por um pronome nulo.

Em (71), apesar de haver alternativas às construções presentes, que poderiam eliminar alguma ambiguidade relativamente ao referente do primeiro e terceiro sujeitos representados, o contexto permite desambiguá-las. No entanto, no segundo caso, o sujeito tem um referente proposicional, o que impede que seja nulo. Este problema resultou da reestruturação do texto de partida levada a cabo pelo tradutor.

(71) a. Se o seu gato começar a apresentar sinais de medo, [-] pode alterar o seu comportamento através de brincadeiras interativas pouco energéticas para que ele se possa distrair. Se [-] for detetado na fase inicial, [-] pode conseguir alterar a mentalidade do seu gato aos despoletar o seu instinto de caça.

b. If a cat begins showing initial signs of fear, behavior modification can be done in the form of lowintensity interactive playtime for distraction. If caught early, you may be able to change his mindset as you trigger his prey-drive.

A opção pelo uso de uma expressão anafórica menos reduzida, por exemplo um pronome realizado, cuja forma permitirá o reconhecimento inequívoco do referente e, como tal, uma resolução adequada da anáfora, resolveria os problemas identificados em (69) e (70) - veja-se (72) e (73). No caso de (71), pelo facto de o sujeito ter um antecedente proposicional, seria adequada a opção por uma anáfora conceptual (cf. (74)).

$$
\text { — Mãe. - Ajoelhei-me perante ela, já que era assim que ela gostava, usando um tom de respeito. }
$$


(73) Mais que na maioria dos designers, as coleções do Kane percepcionam-se sempre profundamente pessoais, por isso era inevitável que os críticos ligassem o tema de 'a Criação que vem da Destruição' do 'Colidir e Consertar' à perda da sua mãe, Christine, que faleceu três dias antes do desfile e no mesmo dia em que ele abriu a sua primeira loja em Londres, em 2015.

(74) Se o seu gato começar a apresentar sinais de medo, pode alterar o seu comportamento através de brincadeiras interativas pouco energéticas para que ele se possa distrair. Se o problema for detetado na fase inicial, pode conseguir alterar a mentalidade do seu gato ao despoletar o seu instinto de caça.

(ii) Uso de uma construção em que a ocorrência de sujeito nulo obriga a uma interpretação específica, não pretendida

Os exemplos em (75) e (76) correspondem a problemas na interpretação dos sujeitos nulos em contextos de coordenação oracional.

(75) a. A família de Dolly ensopou imediatamente a carne viva da sua cara com água e [-] foi rapidamente levada para o hospital.

b. Dolly's family immediately doused the raw flesh of her face with water and she was rushed to hospital.

(76) a. Como muitos líderes do humanismo renascentista, da Vinci não viu uma diferença entre ciência e arte. Para Leonardo, uma disciplina completava a outra e [-] acreditava que o estudo da ciência fazia dele um artista melhor.

b. Like many leaders of Renaissance humanism, da Vinci did not see a divide between science and art. He viewed the two as intertwined disciplines rather than separate ones. He believed studying science made him a better artist.

Como descrevemos anteriormente, quando, numa estrutura de coordenação oracional, o sujeito da segunda oração é nulo, é interpretado como correferente com o sujeito da primeira oração. Assim, embora seja possível que o sujeito da segunda oração seja correferente com uma expressão encaixada no sujeito da primeira oração, este referente não pode ser recuperado por um sujeito nulo. $\mathrm{O}$ facto de os sujeitos das orações coordenadas não serem correferentes obriga ao uso, na segunda oração, de uma anáfora menos reduzida, por exemplo, um pronome lexical. Nestes dois casos, o tradutor introduziu um problema no texto de chegada ao eliminar os pronomes sujeito que se encontram no texto de partida.

O exemplo (77), por sua vez, diz respeito ao estabelecimento das relações de correferência em estruturas de subordinação, em particular, com conjuntivo.

(77) a. A família de Rani começou a preocupar-se e fez com que [-] tivesse alta do hospital, apesar dos protestos dos médicos.

b. Rani's family became concerned and had her discharged from the hospital, despite protests from the doctors.

Como mostrámos na Secção 2.2.2, a ocorrência de sujeito nulo numa oração subordinada de conjuntivo torna, normalmente, não aceitável a interpretação de correferência com o sujeito da frase matriz, pelo que, em (77), o sujeito nulo da subordinada que ocorre no segundo termo coordenado não é correferente com o sujeito (nulo) deste termo (que retoma a referência de a família de Rani). Por outro lado, o facto de a expressão Rani, encaixada no sujeito, não ser proeminente dificilmente permite que essa expressão sirva de antecedente a um pronome nulo. 
O problema identificado nos três exemplos acima poderá ser resolvido com recurso a uma expressão anafórica menos reduzida, por exemplo um pronome realizado:

(78) A família de Dolly ensopou imediatamente a carne viva da sua cara com água e ela foi rapidamente levada para o hospital.

(79) Para Leonardo, uma disciplina completava a outra e ele acreditava que o estudo da ciência fazia dele um artista melhor.

(80) A família de Rani começou a preocupar-se e fez com que ela tivesse alta do hospital, apesar dos protestos dos médicos.

\section{B. Casos em que a estratégia da minimização não é respeitada}

Nos exemplos (81) e (82), o tradutor opta pela utilização reiterada de um pronome lexical quando um pronome nulo permitiria obter a interpretação pretendida, como sugerido em diferentes estudos (vejam-se, em particular, os trabalhos apresentados na Secção 2.3):

(81) a. Mas ele não hesitou. Ele foi diretamente ter com ela e Peyton, de arma em riste e dedo no gatilho.

b. But he didn't hesitate. He came rigth up to her and Peyton, leading with that firearm, finger on the trigger.

(82) a. Ainda assim, Dolly ficou permanentemente marcada e ainda tem dificuldade em respirar por causa dos danos nas fossas nasais. Ela recorda-se do momento em que pediu para se ver ao espelho depois de regressar do hospital para casa.

b. Even so, Dolly is now permanently scarred, and she still has trouble breathing because of the damage to her nostrils. She recalls the moment she asked to look in a mirror after returning home from the hospital.

Nestes dois casos, a forma anafórica mais reduzida - o sujeito nulo - permitiria o reconhecimento do antecedente, pelo que o mais adequado seria optar pela minimização. De facto, como descrevemos na Secção 2.4, em geral, o sujeito nulo de um período de texto tende a ser correferente com o sujeito do período anterior. Neste caso, o problema decorre de uma colagem excessiva ao texto de partida, sem que se tenham em conta as diferenças entre as línguas no que diz respeito ao sujeito nulo.

O exemplo (83) é igualmente ilustrativo de colagem ao texto de partida, o que resultou na realização lexical desnecessária do sujeito.

(83) a. Ela não tinha ideia do que estava a dizer. O que raio estava a fazer? Ela nunca tinha visto tantas armas juntas e muito menos se tinha posto deliberadamente no alcance dessas mesmas, mas ela explodiu e descobriu que dela veio uma força enorme.

b. She had no idea what the hell she was saying. What the hell she was doing. She had never seen so many guns before, much less deliberately put herself within point-blank range of such weapons - but she had snapped and discovered a surprising surge of power came with the unhinge.

Repare-se que ambos os sujeitos assinalados acima deveriam ser nulos: no primeiro caso, porque o sujeito nulo será interpretado como correferente com o sujeito do primeiro período; no segundo caso, porque a realização lexical do segundo termo coordenado induz uma interpretação de referência disjunta relativamente ao sujeito do primeiro termo, quando o que se pretende é uma leitura de correferência. O uso de uma estratégia de minimização como a opção por sujeitos nulos elimina o problema identificado nestes exemplos: 
(84) Mas ele não hesitou. [-] Foi diretamente ter com ela e Peyton, de arma em riste e dedo no gatilho.

(85) Ainda assim, Dolly ficou permanentemente marcada e ainda tem dificuldade em respirar por causa dos danos nas fossas nasais. [-] Recorda-se do momento em que pediu para se ver ao espelho depois de regressar do hospital para casa.

(86) Ela não tinha ideia do que estava a dizer. O que raio estava a fazer? [-] Nunca tinha visto tantas armas juntas e muito menos se tinha posto deliberadamente no alcance dessas mesmas, mas [-] explodiu e descobriu que dela veio uma força enorme.

Embora ilustre o mesmo tipo de problema, o dado seguinte apresenta contornos específicos:

(87) a. Alinhando os ombros, o atirador virou-se para o outro lado - e ele estava ciente de que havia outra razão para ele ter parado. Mas ele não queria admiti-la de todo.

b. Squaring his shoulders, he face off - and was aware that there was probably another reason why he halted. But he refused to acknowledge it in any way.

A ocorrência de três pronomes realizados impossibilita o reconhecimento do referente pretendido para cada um deles, uma vez que existem dois referentes em competição: o referente associado à expressão $o$ atirador e a personagem que constitui o tópico principal do episódio narrado. A observação do contexto discursivo levanos a concluir que se pretende que os três pronomes sejam correferentes, sendo o referente a personagem tópico. Neste caso, para tornar clara a relação anafórica que se estabelece entre os três pronomes e ser evidente o facto de o seu referente ser exterior a esta sequência textual, torna-se necessária a ocorrência de um pronome lexical a realizar o primeiro sujeito, para impedir a correferência com o referente de o atirador, e os dois sujeitos seguintes devem ser substituídos por pronomes nulos, para induzir a correferência com esse sujeito.

(88) Alinhando os ombros, o atirador virou-se para o outro lado - e ele estava ciente de que havia outra razão para [-] ter parado. Mas [-] não queria admiti-la de todo.

\section{Casos em que o sujeito foi realizado por uma anáfora com realização lexical inadequada}

Um outro problema que se encontra nos dados observados diz respeito à seleção de uma forma anafórica inadequada, como está ilustrado em seguida.

(89) a. Desta forma, Richis não parecia particularmente preocupado com o facto de Laure poder vir a tornar-se uma das vítimas do assassino já que era do conhecimento geral que ele não atacava nem crianças nem mulheres adultas (...).

b. And thus he had not been seriously afraid that Laure would be one of the murderer's victims, since everyone knew that he attacked neither children nor grown women (...)

(90) a. O problema começou quando um homem das redondezas - duas vezes mais velho do que Dolly - não a deixava em paz. Este começou a perseguir a estudante de doze anos, fazendo-lhe comentários obscenos e sugerindo que deveriam dormir juntos.

b. The trouble began when a man from the same neighbourhood - twice Dolly's age - wouldn't leave her alone. He started stalking the 12-year-old schoolgirl, making lewd remarks and suggesting they should sleep together. 
Estes dados tornam evidente a dificuldade ou hesitação na opção entre duas formas anafóricas pronominais com realização lexical: o pronome pessoal e o pronome demonstrativo. Quando existem referentes em competição, a utilização do pronome demonstrativo este permite o reconhecimento do referente a partir da proximidade linear, dado que este pronome estabelece uma relação anafórica com o referente mais próximo (cf. Secção 2.4). Em (89a), o uso do pronome pessoal ele não permite um reconhecimento inequívoco do referente mais próximo, que é o pretendido. Numa situação contrária, em (90a), o uso do pronome demonstrativo este obriga ao estabelecimento de um nexo anafórico com o referente mais próximo, que não é o pretendido.

Assim, em (89a), o pronome pessoal ele deve ser substituído pelo pronome demonstrativo este, de forma a que o nexo anafórico se estabeleça com o referente mais próximo (91). Em (90a), o pronome demonstrativo este deve ser substituído pelo pronome pessoal ele, de forma a que o nexo anafórico se estabeleça com o referente pretendido, que não é o mais próximo (92).

(91) Desta forma, Richis não parecia particularmente preocupado com o facto de Laure poder vir a tornar-se uma das vítimas do assassino já que era do conhecimento geral que este não atacava nem crianças nem mulheres adultas (...).

(92) O problema começou quando um homem das redondezas - duas vezes mais velho do que Dolly -não a deixava em paz. Ele começou a perseguir a estudante de doze anos, fazendo-lhe comentários obscenos e sugerindo que deveriam dormir juntos.

\section{Conclusões}

Partindo da ideia de que a produção e a compreensão de um texto envolvem a capacidade de estabelecer relações entre os elementos que ocorrem na superfície textual e que asseguram a coesão textual, centrámo-nos, no presente trabalho, nas estratégias de construção de cadeias de referência, em particular naquelas que envolvem a posição de sujeito em frases finitas. Para tal, considerámos duas línguas distintas no que diz respeito ao fenómeno do sujeito nulo, o inglês e o português (neste último caso, descrevemos as restrições à ocorrência de sujeitos nulos referenciais), uma vez que foi nosso objetivo apresentar dados recolhidos de traduções envolvendo esse par linguístico realizadas por estudantes universitários.

No essencial, os dados do português que apresentámos corroboram a generalização de que as expressões nominais expandidas são usadas quando a sua presença é necessária para o reconhecimento do referente, e, quando tal não é necessário, se opta pela minimização, usando-se expressões mínimas, como os pronomes com realização lexical, ou, no caso do português, formas pronominais nulas, quando o seu antecedente é recuperável linguística ou discursivamente.

Os dados recolhidos das traduções revelaram essencialmente três tipos de problemas:

(i) Utilização indevida de sujeitos nulos na língua de chegada, o que impede a identificação adequada do antecedente - ou o antecedente não é de todo recuperável ou o antecedente que é recuperado não é o que permite obter a leitura pretendida.

(ii) Não aplicação da estratégia de minimização nos casos em que a mesma é preferida - sendo o antecedente estruturalmente proeminente, as formas pronominais nulas são preferidas relativamente às formas pronominais lexicais.

(iii) Utilização de anáforas com realização lexical inadequada, com impacto na interpretação.

Muitas das opções de tradução inadequadas que surgem parecem decorrer de uma estratégia de decalque das propriedades da língua de partida: sendo o inglês uma língua em que o sujeito é obrigatoriamente realizado, o tradutor opta, também em português, por formas realizadas, independentemente de estarem reunidas as condições gramaticais e/ou discursivas para a omissão do sujeito, o que pode levar ou a estruturas agramaticais 
ou a situações de ambiguidade referencial. Noutros casos, pelo contrário, o tradutor sobregeneraliza a omissão do sujeito, inviabilizando o reconhecimento do referente pretendido e criando, por vezes, situações de ambiguidade referencial. Qualquer uma destas situações constitui um problema e um obstáculo para a adequação do texto traduzido, podendo levar a dificuldades de interpretação para o leitor ou mesmo a uma deturpação do texto.

No quadro da tradução em contexto académico, impõe-se, assim, um treino que promova o conhecimento explícito dos pares de línguas relevantes, que deve necessariamente iniciar-se pela descrição sistemática e comparada das mesmas.

\section{Referências}

Ariel, Mira (1996) Referring expressions and +/- coreference distinction. In T. Fretheim \& J. Gundel (orgs.) Reference and referent accessibility. Amsterdam: John Benjamins Publishing Company, pp. 13-35.

Barbosa, Pilar (1995) Null subjects. PhD dissertation, MIT.

Barbosa, Pilar (2018) Controlled overt pronouns as specificational predicates. In A. L. Santos \& A. Gonçalves (orgs.) Complement clauses in Portuguese: Syntax and acquisition. Amsterdam: John Benjamins. pp. $129-185$

Beaugrande, Robert-Alain \& Wolfgang Dressler (1981) Introduction to Text Linguistics. London: Longman.

Brito, Ana Maria (1991) A sintaxe das orações relativas em português. Porto: INIC.

Cardinaletti, Anna \& Michael Starke (1999) The typology of structural deficiency: A case study of three classes of pronouns. In H.van Riemsdijk (org) Clitics in the Languages of Europe. Berlin/New York: Mouton de Gruyter, pp. 145-233.

Cardoso, Adriana \& Catarina Magro (2013) Problemas de coesão referencial na escrita académica em português. Comunicação apresentada na $3^{a}$ Conferência Internacional em Gramática e Texto - GRATO 2013. Lisboa, dezembro 2013.

Carrilho, Ernestina (2005) Expletive ele in European Portuguese dialects. Tese de doutoramento, Universidade de Lisboa.

Carrilho, Ernestina (2008) Sobre o expletivo ele em português europeu. Estudos de Lingüística Galega 1, pp. 7-26.

Chomsky, Noam (1981) Lectures on Government and Binding. Foris, Dordrecht.

Chomsky, Noam (1982) Some concepts and consequences of the Theory of Government and Binding. Cambridge, Mass.: The MIT Press.

Clark, Robin \& Prashant Parikh (2007) Game theory and discourse anaphora. Journal of Logic, Language and Information 16 (3), pp. 265-282.

Costa, Armanda, Gabriela Matos \& Paula Luegi (2010) Processamento de relações anafóricas com sujeitos omitidos em português europeu. In A. M. Brito et al. (orgs.) Textos Seleccionados, XXV Encontro Nacional da Associação Portuguesa de Linguística. Porto: APL, pp. 351-364.

d'Alessandro, Roberta (2015) Null subjects. In A. Fábregas, J. Mateu, \& M. Putnam (orgs.) Contemporary linguistic parameters. London: Bloomsbury, pp. 201-226.

Duarte, Inês (2003) Aspectos linguísticos da organização textual. In M. H. Mateus et al. (orgs.) Gramática da língua portuguesa. Lisboa: Caminho, pp. 85-123.

Duarte, Inês \& M. Cristina Figueiredo Silva (2016) The Null Subject Parameter and the structure of the sentence in European and Brazilian Portuguese. In W. L. Wetzels, S. Menuzzi \& J. Costa (orgs.) The handbook of Portuguese linguistics. Malden: Wiley Blackwell, pp. 234-253.

Fox, Barbara A. (1987) Discourse structure and anaphora: Written and conversational English. Cambridge: Cambridge University Press. 
Givón, Talmy (1983) Topic continuity in discourse: a quantitative cross-language study. Amsterdam: John Benjamins.

Givón, Talmy (1985) Iconicity, isomorphism and non-arbitrary coding in syntax. In J. Haiman (org.) Iconicity in syntax. Amsterdam: John Benjamins, pp. 187-219.

Givón, Talmy (1990) Syntax: a functional-typological introduction. Amsterdam: John Benjamins.

Gonçalves, Anabela \& Madalena Colaço (2018) A construção de cadeias de referência no contexto da tradução inglês-português. Comunicação apresentada no XIII Congreso Internacional de Lingüística Xeral, Universidad de Vigo, junho de 2018.

Grice, Paul (1989) Studies in the way of words. Cambridge, MA: Harvard University Press.

Grosz, Barbara J., Aravind K. Joshi \& Scott Weinstein (1995) Centering: A framework for modeling the local coherence of discourse. Computation Linguistics 21 (2), pp. 203-225.

Gundel, Jeanette K., Nancy Hedberg \& Ron Zacharski (1993). Cognitive status and the form of referring expressions in discourse. Language 69, pp. 274-307.

Hinds, John (1978) Anaphora in discourse. Edmonton: Linguistic Research Inc.

Hinds, John (1979) Organizational patterns in discourse. In T. Givón (org.) Discourse and syntax. London: Academic Press, pp. 135-157.

Holmberg, Anders (2005) Is there a little pro? Evidence from Finnish. Linguistic Inquiry 36 (4), pp. 533-564.

Holmberg, Anders (2010) Null subject parameters. In T. Biberauer et al. (orgs.) Parametric variation: Null subjects in Minimalist Theory. Cambridge: Cambridge University Press, pp. 88-124.

Huang, Yan (1989) Anaphora in Chinese: toward a pragmatic analysis. PhD Dissertation. Univ. of Cambridge.

Huang, Yan (2000) Discourse anaphora: four theoretical models. Journal of Pragmatics 32, pp. 151-176.

Kayne, Richard (1980) Extensions of binding and case-marking. Linguistic Inquiry 11 (1), pp.75-96.

Lambrecht, Knud (1994) Information structure and sentence form: a theory of topic, focus and the mental representations of discourse referents. Cambridge: Cambridge University Press.

Levinson, Stephen C. (1987) Pragmatics and the grammar of anaphora. Journal of Linguistics, 23, pp. 379-434.

Levinson, Stephen C. (1991) Pragmatic reduction of the Binding Condition revisited. Journal of Linguistics, 27, pp. 107-161.

Levinson, Stephen C. (1995) Three levels of meaning. In Palmer, F. (org.) Grammar and meaning. Cambridge: Cambridge University Press, pp. 90-115.

Lobo, Maria (2013a) Dependências referenciais. In Raposo et al. (orgs.) Gramática do Português. Lisboa: FCG, pp. 2177-2227.

Lobo, Maria (2013b) Sujeito nulo: sintaxe e interpretação. In Raposo et al. (orgs.) Gramática do Português. Lisboa: FCG, pp. 2309-2335.

Lobo, Maria \& Carolina Silva (2016) Ambiguidade pronominal em orações adverbiais do português europeu: crianças vs. adultos. Revista da Associação Portuguesa de Linguística 2, pp. 319-338.

Marques, Rui (2018) Subjunctive and subject obviation in Portuguese. In A. L. Santos \& A. Gonçalves (orgs.) Complement clauses in Portuguese: Syntax and acquisition. Amsterdam: John Benjamins. pp. 213-240.

Mendes, Amália (2013) Organização textual e articulação de orações. In Raposo et al. (orgs.) Gramática do Português. Lisboa: FCG, pp. 1691-1755.

Perlmutter, David (1971) Deep and surface structure: Constraints in Syntax. New York: Holt, Rinehart \& Winston.

Reinhart, Tanya (1983) Anaphora and semantic interpretation. Chicago: The University of Chicago Press.

Rizzi, Luigi (1982) Issues in Italian syntax. Dordrecht: Foris.

Rizzi, Luigi (1986) Null objects in Italian and the theory of pro. Linguistic Inquiry 17 (3), pp. 501-557.

Roberts, Ian (2010) A deletion analysis of null subjects. In T. Biberauer et al. (orgs.) Parametric variation: Null subjects in Minimalist Theory. Cambridge: Cambridge University Press, pp. 58-87. 
Anabela Gonçalves e Madalena Colaço

Roberts, Ian \& Anders Holmberg (2010) Introduction: Parameters in Minimalist Theory. In T. Biberauer et al. (orgs.) Parametric variation: Null subjects in Minimalist Theory. Cambridge: Cambridge University Press, pp. 1-57.

Safir, Ken (2004) The syntax of anaphora. Oxford: Oxford University Press. 